\title{
P-Selectin Glycoprotein Ligand-1 (PSGL-1) Expressing CD4 T Cells Contribute Plaque Instability in Acute Coronary Syndrome
}

\author{
Kazutaka Kitamura, MD; Kayoko Sato, MD, PhD; Motoji Sawabe, MD, PhD; \\ Masayuki Yoshida, MD, PhD; Nobuhisa Hagiwara, MD, PhD
}

\begin{abstract}
Background: Adhesion molecules have essential roles in the development of atherosclerosis. We investigated whether P-selectin glycoprotein ligand-1 (PSGL-1)-expressing CD4 T cells contribute to plaque instability in acute coronary syndrome (ACS).

Methods and Results: We studied the adhesion molecules on CD4 T cells from consecutive patients with ACS treated with thrombus-aspirating device and compared them with healthy controls $(n=48$ each). Blood, thrombi, and plaque samples from the culprit coronary arteries were collected by thrombus aspiration performed during emergency coronary artery angiography. According to flow cytometry results, peripheral CD4 T cells from ACS patients strongly expressed PSGL-1 and integrin $\beta 2$ ( $P<0.05$ for both) more than those from controls; culprit coronary arteries contained an abundance of PSGL- $1+(P<0.001)$ but not integrin $\beta 2+C D 4 T$ cells. In addition, immunohistochemical analysis of the thrombus-aspirating device samples revealed numerous PSGL-1+CD4 T cells in plaques from the culprit lesions. Results from the selectin-binding assay demonstrated that activated PSGL-1+CD4 T cells from ACS patients bound to $P$ - or E-selectin after triggering the T-cell receptor, and adhered to endothelial cells under laminar flow conditions $(P<0.05$ and $P<0.05$, respectively), inducing their apoptosis $(P<0.01)$ via activated caspase- 3 , which correlated with PSGL-1 expression $(R=0.788, P=0.021)$ and was suppressed by application of a $P S G L-1$-specific antibody $(P<0.05)$.
\end{abstract}

Conclusions: PSGL-1 contributed to cytotoxic CD4 T cell homing to the culprit coronary artery and promoted plaque instability in ACS.

Key Words: Acute coronary syndrome; Atherosclerosis; Cell adhesion molecules; Lymphocytes; Plaque vulnerability

$A$ therosclerosis and cardiovascular diseases such as acute coronary syndrome (ACS) are the major causes of cardiovascular death. Both innate and adaptive immunity have been proposed as playing important roles in atherosclerosis development and progression. ${ }^{1-5}$ Vulnerable plaques, which can trigger ACS, have particular pathological characteristics, including a large lipid core, thin fibrous capsule, neovascularization, hematoma, apoptosis of vascular smooth muscle cells (VSMCs) and endothelial cells (ECs), and numerous inflammatory infiltrates. ${ }^{6-9}$ Activated, cytotoxic clusters of differentiation (CD)4-expressing T cells (termed CD4 T cells) play a pivotal role in acquired immune responses and are observed in ACS, inducing the apoptosis of VSMCs and ECs. ${ }^{10-16}$

Leukocytes roll or crawl along the activated endothelium before firmly adhering to the vessel wall, which is a critical first step in their recruitment into the wall. Adherent, transmigrating leukocytes are activated in situ and may cause atherosclerotic plaque instability and damage to tissues that include ECs and VSMCs. This process is largely mediated by cellular adhesion molecules expressed on both vascular ECs and leukocytes. ${ }^{17,18}$ Several adhesion molecules on $\mathrm{T}$ cells have been identified, including E-selectin ligand, P-selectin glycoprotein ligand-1 (PSGL-1), integrin $\alpha \mathrm{M} / \beta 2$ (Mac1), integrin $\alpha 4 / \beta 1$, and $\alpha \mathrm{L} / \beta 2$ (lymphocyte function-associated antigen 1, LFA-1). The binding of these molecules to E- and P-selectin, intercellular cell adhesion molecule (ICAM)-1, and vascular cell adhesion molecule (VCAM)-1 on ECs initiates the formation of atherosclerotic plaques. Focal expression of ICAM-1and E- selectin has been consistently observed in human atherosclerotic plaques, ${ }^{19}$ however, it is still unclear how T-cell adhesion molecules contribute to atherosclerosis development and the incidence of ACS.

In this study we investigated T-cell adhesion molecules in the peripheral blood and in the culprit coronary arteries

Received November 21, 2017; revised manuscript received April 30, 2018; accepted May 7, 2018; released online June 30 , 2018 Time for primary review: 20 days

Department of Cardiology, Tokyo Women's Medical University, Tokyo (K.K., K.S., N.H.); Section of Molecular Pathology, Graduate School of Health Care Sciences (M.S.), Life Sciences and Bioethics Research Center (M.Y.), Tokyo Medical and Dental University, Tokyo, Japan

Mailing address: Kayoko Sato, MD, PhD, Department of Cardiology, Tokyo Women's Medical University, 8-1 Kawada-cho, Shinjyuku-ku, Tokyo 162-8666, Japan. E-mail: sato.kayoko@twmu.ac.jp

ISSN-1346-9843 All rights are reserved to the Japanese Circulation Society. For permissions, please e-mail: cj@j-circ.or.jp 
in ACS, and analyzed thrombi and atherosclerotic plaques in samples from culprit coronary arteries obtained from thrombus-aspiration therapy.

\section{Methods}

\section{Study Population}

The study population consisted of 48 consecutive patients who underwent thrombus-aspiration therapy for ACS ( $73 \%$ male, $68 \pm 11$ years old), including 27 cases of acute myocardial infarction and 21 cases of unstable angina pectoris. Blood was drawn from the peripheral vein at the time of admission to the Coronary Care Unit of Tokyo Women's Medical University, and blood, thrombus, and plaque samples from the culprit coronary arteries were collected at the time of thrombus-aspiration therapy during emergency coronary artery angiography (Table). ACS was defined according to criteria established by the American Heart Association. The control group consisted of 48 healthy patients (NC; $75 \%$ male, $51 \pm 9.0$ years old) without cardiovascular disease, diabetes mellitus, hypertension, or hypercholesterolemia, and who were not smokers at the time of enrollment. Individuals with infectious, autoimmune, or neoplastic diseases were excluded from the study. The study was conducted in accordance with the Declaration of Helsinki. The Tokyo Women's Medical University Institutional Review Board approved all protocols, and informed consent was given by all subjects.

\section{Cell Culture}

Fresh peripheral blood mononuclear cells (PBMCs) were isolated from peripheral or culprit coronary arterial blood using Ficoll-Hypaque (Amersham Biosciences, Brown Deer, WI, USA). CD4 T cells were isolated (purity $\geq 95 \%$ ) by negative selection using the Rosette Sep CD4 T Cell Enrichment Kit (StemCell Technologies, Vancouver, Canada) and cultured in Roswell Park Memorial Institute (RPMI) 1640 medium containing 10\% fetal bovine serum (FBS), $100 \mathrm{U} / \mathrm{mL}$ penicillin, $100 \mu \mathrm{g} / \mathrm{mL}$ streptomycin, and $2 \mathrm{mmol} / \mathrm{L}$ L-glutamine. THP-1 cells were obtained from the American Type Culture Collection (Manassas, VA, USA) and grown in the same medium as the primary CD4 cells. Human umbilical vein (HUV) ECs were purchased from Lonza Walkersville (Walkersville, MD, USA) and propagated on collagen-coated tissue culture plates in EmGM-2 EC medium (Cambrex, Walkersville, MD, USA); cells from passages $4-6$ were used.

\section{Flow Cytometry}

Cytometric analysis was performed by labeling PBMCs with fluorescein isothiocyanate (FITC)-, phycoerythrin (PE)-, or Cy5-conjugated monoclonal antibodies against the following human proteins: CD4 (FITC and PE-Cy5), CD69 (FITC), and PSGL-1/CD162 (PE) (all from BD Pharmingen, San Jose, CA, USA); L-selectin/CD62L (FITC) (Santa Cruz Biotechnology, Santa Cruz, CA, USA); and integrin $\beta 2 / \mathrm{CD} 18$ (FITC) and $\alpha \mathrm{M} / \mathrm{CD} 11 \mathrm{~b}$ (PE-Cy5) (both from BioLegend, San Diego, CA, USA). The expression levels of each molecule on the T cells were analyzed by flow cytometry (BD FACSCalibur, Franklin Lakes, NJ, USA), and data were analyzed using Win MDI software (Scripps Research Institute, La Jolla, CA, USA).

To investigate caspase-3-dependent apoptosis, freshly isolated CD4 T cells were cocultured on a HUVEC monolayer at an effector:target ratio of $5: 1$ with $50 \mathrm{ng} / \mathrm{mL}$ tumor

\begin{tabular}{|lr|}
\hline \multicolumn{2}{|l|}{ Table. Clinical Characteristics of Patients With ACS } \\
Patients, $\mathrm{n}$ & 48 \\
Sex (male), $\mathrm{n}(\%)$ & $35(73)$ \\
Age, mean $\pm \mathrm{SD}$, years & $68 \pm 11$ \\
$\mathrm{AMI}, \mathrm{n}(\%)$ & $27(56)$ \\
Cardiovascular risk factors & \\
Diabetes mellitus, $\mathrm{n}(\%)$ & $22(46)$ \\
Hypertension, $\mathrm{n}(\%)$ & $38(72)$ \\
Hypercholesterolemia, $\mathrm{n}(\%)$ & $34(79)$ \\
Smoking, $\mathrm{n}(\%)$ & $21(44)$ \\
Family history of CAD, $\mathrm{n}(\%)$ & $7(15)$ \\
BMI, mean $\pm \mathrm{SD}, \mathrm{kg} / \mathrm{m}^{2}$ & $24.6 \pm 9.0$ \\
Cr, mean $\pm \mathrm{SD}, \mathrm{mg} / \mathrm{dL}$ & $0.9 \pm 0.3$ \\
Medications & \\
$\beta$-blockers, $\mathrm{n}(\%)$ & $14(29)$ \\
ACEI/ARBs, $\mathrm{n}(\%)$ & $26(54)$ \\
Aspirin, $\mathrm{n}(\%)$ & $23(48)$ \\
Statin, $\mathrm{n}(\%)$ & $19(40)$ \\
Triglycerides, mean $\pm \mathrm{SD}, \mathrm{mg} / \mathrm{dL}$ & $99.2 \pm 59$ \\
HDL-C, mean $\pm \mathrm{SD}, \mathrm{mg} / \mathrm{dL}$ & $48 \pm 16$ \\
LDL-C, mean $\pm \mathrm{SD}, \mathrm{mg} / \mathrm{dL}$ & $114 \pm 35$ \\
\hline
\end{tabular}

$\mathrm{ACEl}$, angiotensin-converting enzyme; AMI, acute myocardial infarction; ARB, angiotensin II receptor blocker; BMI, body mass index; $C A D$, coronary artery disease.

necrosis factor (TNF)- $\alpha$ used as positive control for $3 \mathrm{~h}$ in RPMI medium with $2 \%$ FBS. CD4 T cells were then removed with phosphate-buffered saline (PBS) containing $10 \%$ FBS. HUVECs were collected by trypsinization and washed with cold PBS, then incubated in BD Cytofix/ Cytoperm solution (BD Pharmingen) for $20 \mathrm{~min}$ on ice. HUVECs were pelleted by centrifugation, washed twice with BD Perm/Wash buffer (BD Pharmingen), stained with PE-conjugated rabbit anti-activated caspase-3 antibody (BD Pharmingen) in BD Perm/Wash buffer for $30 \mathrm{~min}$ at room temperature, and analyzed by flow cytometry.

\section{Selectin-Binding Assay}

To examine selectin binding, PBMCs were stimulated with and without the anti-human CD3 monoclonal antibody Orthoclone OKT3 (Janssen Pharmaceutical, Tokyo, Japan) for $48 \mathrm{~h}$, then incubated with $50 \mathrm{ng} / \mu \mathrm{L}$ recombinant human E- or P-selectin/Fc chimera (R\&D Systems, Minneapolis, MN, USA). Cells were then labeled with IgG F1-FITC (Sigma-Aldrich, St. Louis, MO, USA), CD4-PE-Cy5, CD69-FITC, or CD162-PE monoclonal antibodies followed by flow cytometric analysis.

\section{Adhesion Assay Under Laminar Flow}

The adhesion assay under laminar flow conditions was performed as previously described. ${ }^{20,21}$ Briefly, HUVECs were stimulated with $\mathrm{TNF} \alpha(10 \mu \mathrm{g} / \mathrm{mL})$ for $4 \mathrm{~h}$ on coverslips and then positioned in a flow chamber mounted on an IX80 inverted microscope (Olympus, Shinjuku, Tokyo). The stimulated HUVEC monolayer was immersed in a perfusion medium $(0.2 \% \mathrm{FBS}$ in $\mathrm{PBS})$ for $3 \mathrm{~min}$, after which CD4 T cells $\left(1 \times 10^{6} / \mathrm{mL}\right)$ were drawn through the chamber using a syringe pump for $10 \mathrm{~min}$ at a controlled flow rate to generate a shear stress of 1.0 dyne $/ \mathrm{cm}^{2}$. THP- 1 cells $\left(1 \times 10^{6} / \mathrm{mL}\right)$ were drawn through the chamber as a 
A
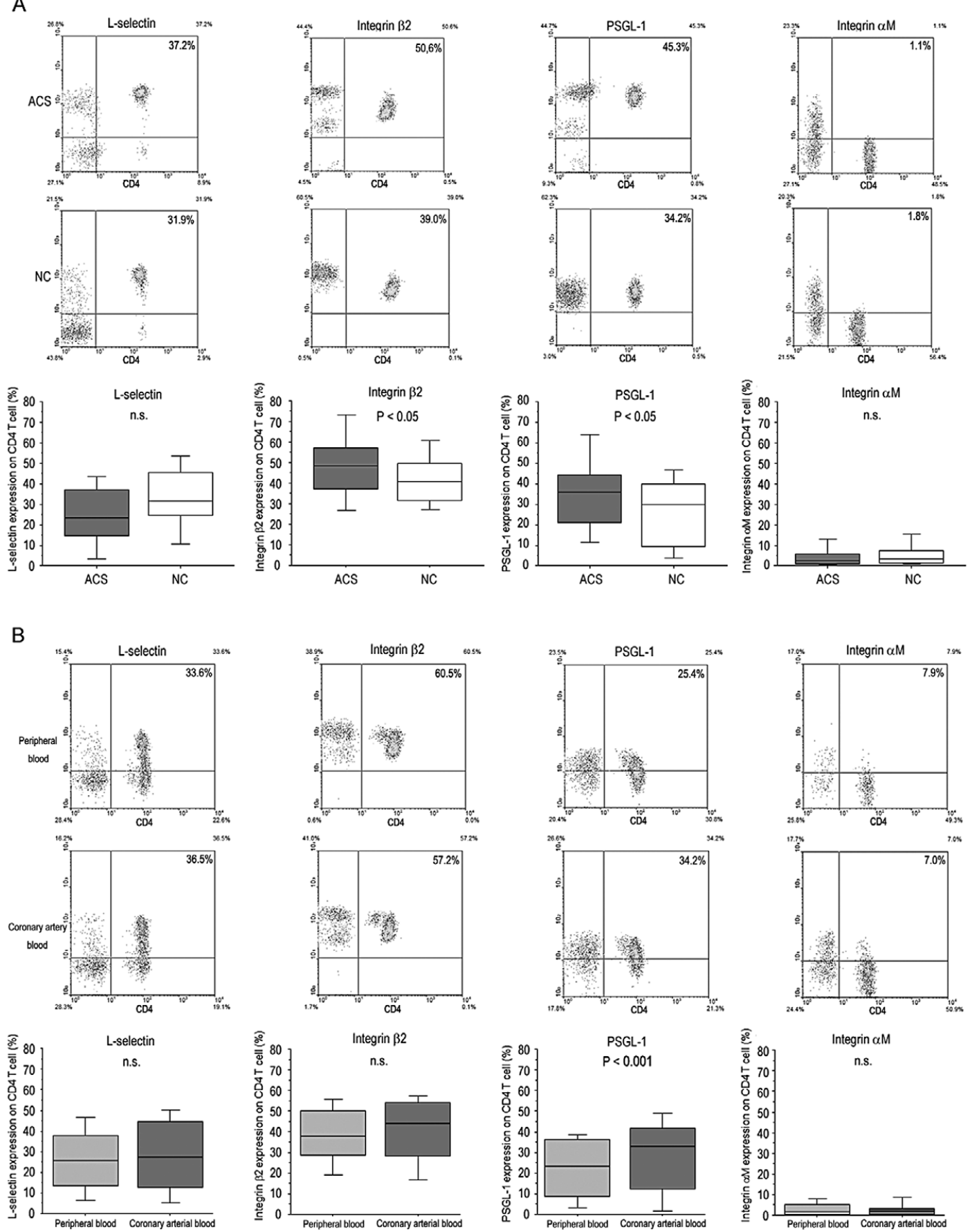

Figure 1. PSGL-1 is robustly expressed on CD4 T cells in culprit coronary arterial blood from patients with acute coronary syndrome (ACS). (A) Adhesion molecule expression on CD4 T cells in peripheral blood from ACS and normal controls (NC) as examined by flow cytometry. (B) Expression of adhesion molecules on CD4 T cells from ACS in peripheral and culprit coronary arterial blood. Representative dot plats and box plots displaying the median are shown, where the 25th and 75th percentiles are represented by the box and the 10th and 90th percentiles are represented as whiskers. n.s., not significant.

control. Rolling and adherent THP-1 and CD4 T cells on the HUVECs were recorded in 15 different fields for randomly selected 15 -s intervals using a video camera attached to the microscope. The number of rolling and adherent THP-1 and CD4 T cells on the HUVECs was determined by analyzing video images on a computer.

\section{Immunohistochemistry}

Samples obtained from the thrombus-aspirating device were fixed in a 4\% paraformaldehyde neutral buffer solu- 


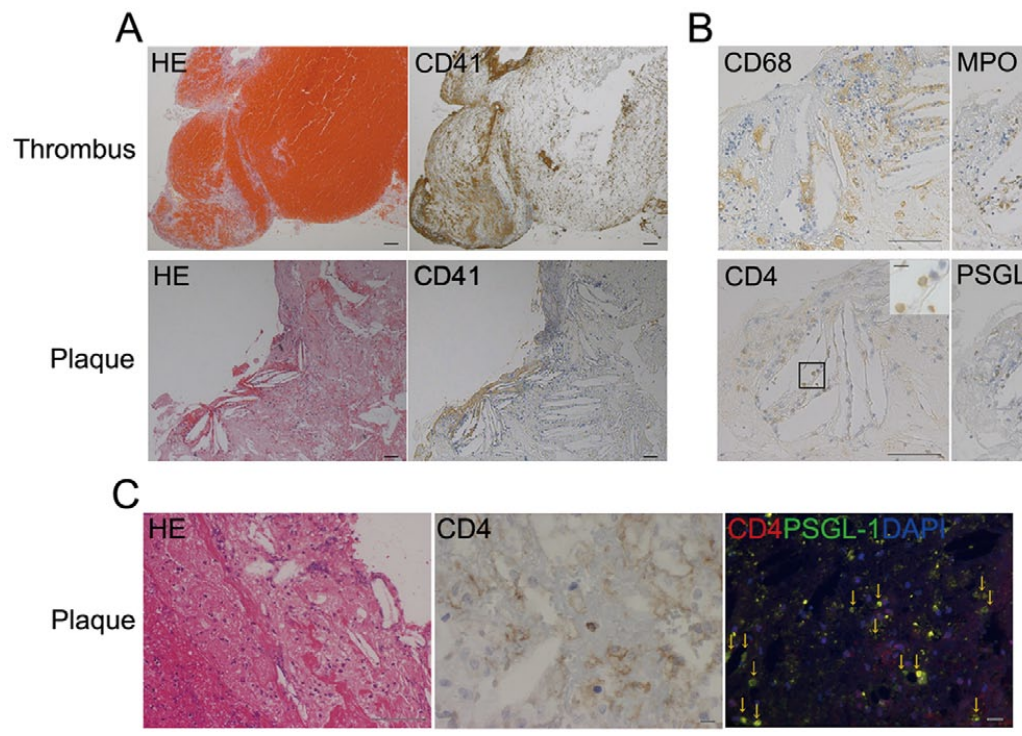

Figure 2. PSGL-1-expressing CD4 T cells are enriched in thrombi and plaques from culprit coronary arteries. Serial paraffinembedded sections of samples obtained from thrombus-aspirating devices used for treating ACS patients. (A) Hematoxylin and eosin (H\&E) staining and CD41-positive platelets and thrombus. (B) CD68-positive macrophages, MPO-positive neutrophils, CD4-positive T cells, and PSGL-1-positive T cells. Immunoreactivity visualized by a reaction with diaminobenzidine (brown). (C) H\&E staining, CD4-positive T cells (brown), and double staining for CD4 (Texas red) and PSGL-1(FITC) in the plaque. Nucleus stained with 4'6-diamidino-2-phenylindole dihydrochloride (DAPI). PSGL-1-expressing CD4 T cells (arrowheads). Original magnifications of $\times 50(\mathbf{A})$ and $\times 200$ (B and H\&E in C) are shown; areas enclosed by the inserts in (B) and double staining in (C) are shown at higher magnification (×400). Scale bars: $100 \mu \mathrm{m}(\mathbf{A}), 50 \mu \mathrm{m}$ (B and H\&E in C), $10 \mu \mathrm{m}$ (inserts in B, CD4 and double staining in $\mathbf{C})$. ACS, acute coronary syndrome.

tion (Nacalai Tesque Inc., Kyoto, Japan), embedded in paraffin, and sectioned at a thickness of $4 \mu \mathrm{m}$. The sections were deparaffinized, stained with hematoxylin and eosin, and labeled with monoclonal antibodies against the following human proteins: glycoprotein (GP)IIb/CD41, CD68 (both from Dako, Glostrup, Denmark); myeloperoxidase (MPO), PSGL-1 (CD162) (both from Novocastra, Wetzlar, Germany); CD4 (both from Nichirei Bioscience, Tokyo, Japan). Brown color was developed by peroxidase solution (ABC-peroxidase kit; Vector Laboratories, Burlingame, CA, USA) and 3,3-diaminobenzidine (DAB) (Dako) as the chromogen. For double staining, red color was developed with Texas red and green color with FITC. Nuclei were stained with 4>6-diamidino-2-phenylindole dihydrochloride (DAPI; Sigma-Aldrich), and then analyzed with an imaging system (Leica Microsystems, Wetzlar, Germany).

\section{Apoptosis Assay}

To detect CD4 T-cell-mediated apoptosis, HUVECs were stained with $1 \mu \mathrm{g} / \mathrm{mL}$ DAPI for $30 \mathrm{~min}$. Freshly isolated CD4 T cells were then cocultured on a HUVEC monolayer at an effector:target ratio of 5:1 for $3 \mathrm{~h}$ in phenol red-free RPMI medium supplemented with $2 \%$ fetal bovine serum (FBS). Apoptosis was identified by characteristic nuclear changes observed by fluorescence microscopy (Leica Microsystems); data are presented as percentages of the total number of HUVEC nuclei. PSGL-1-mediated apoptosis was evaluated by pretreating CD4 T cells with $10 \mu \mathrm{g} / \mathrm{mL}$ neutralizing anti-human PSGL-1 antibody (4RA10; BD Pharmingen) or $10 \mu \mathrm{g} / \mathrm{mL} \operatorname{IgG}$ (IgG $\kappa$ isotype control; BioLegend) as a control for $20 \mathrm{~min}$ on ice prior to analysis.
To detect poly(ADP-ribose) polymerase (PARP) cleavage, fresh CD4 $\mathrm{T}$ cells were cocultured on a HUVEC monolayer at an effector:target ratio of $5: 1$ with $50 \mu \mathrm{g} / \mathrm{mL}$ $\mathrm{TNF}-\alpha$ used as a positive control for $3 \mathrm{~h}$ and then washed with PBS, fixed in $3.7 \%$ formaldehyde, and treated with $0.1 \%$ Triton X-100 in 3\% bovine serum albumin solution. HUVECs were then labeled with purified mouse antihuman PARP antibody (BD Pharmingen), PE-conjugated goat anti-mouse $\mathrm{IgG}$, and DAPI for $1 \mathrm{~h}$ at room temperature, washed with PBS, and analyzed by fluorescence microscopy.

\section{Statistical Analysis}

Data were analyzed using Student's t-test for independent or paired samples. In experiments with skewed distributions, data were analyzed with the Mann-Whitney U test. $\mathrm{P}$-values $<0.05$ were considered statistically significant. Results are shown as the mean $\pm \mathrm{SD}$ and as box plots with medians and 5 th percentile ranges.

\section{Results}

PSGL-1-Expressing CD4 T Cells in Blood, Thrombi, and Plaques From the Culprit Coronary Arteries of ACS Patients To investigate whether adhesion molecules on CD4 T cells differed between ACS patients and NC, the L-selectin, integrin $\beta 2$, PSGL-1, and integrin $\alpha \mathrm{M}$ expression on peripheral blood CD4 T cells was examined by flow cytometry. The ratio of integrin $\beta_{2}$ and PSGL-1 expression on CD4 T cells was higher in ACS patients than in NC $(\mathrm{P}<0.05$; Figure 1A). To determine whether adhesion mol- 

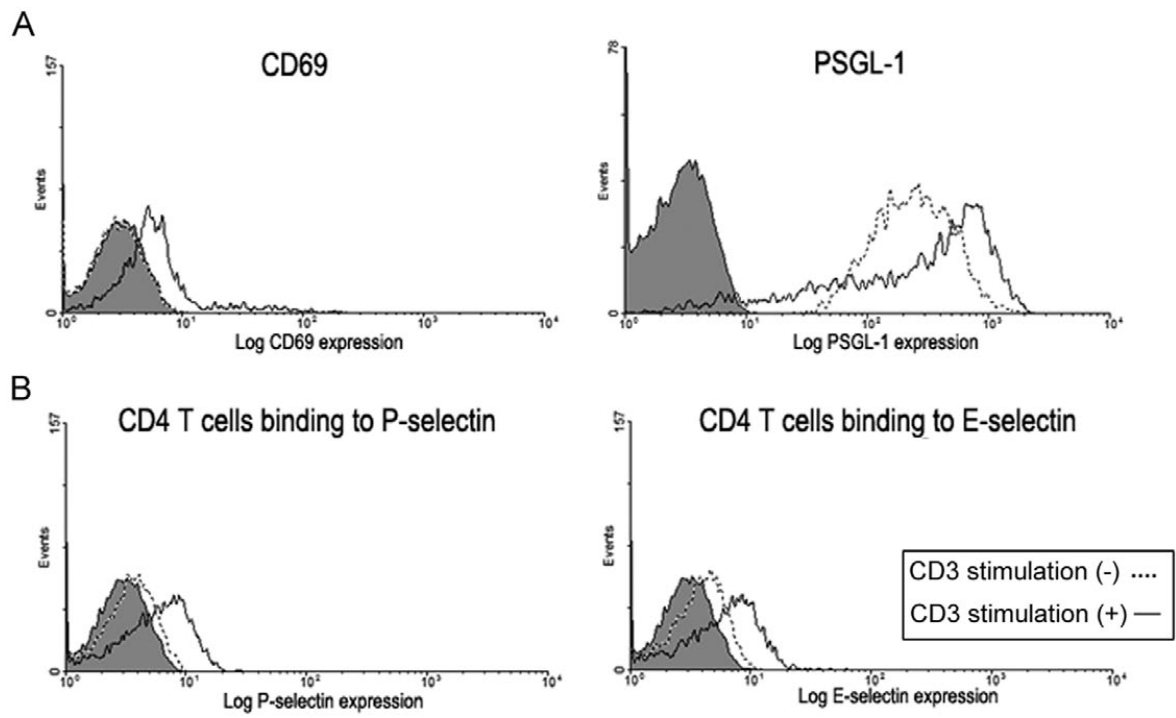

Figure 3. PSGL-1-expressing CD4 T cells bind E- and P-selectin. Fresh PBMCs were stimulated with (solid line) and without (broken line) anti-human CD3 antibody for 48 h, and examined for (A) CD69 or PSGL-1 expression on CD4 T cells, while (B) CD4 T cell binding to P- or E-selectin was analyzed by flow cytometry. The shaded area in the histograms shows the isotype control. PBMC, peripheral blood mononuclear cell.
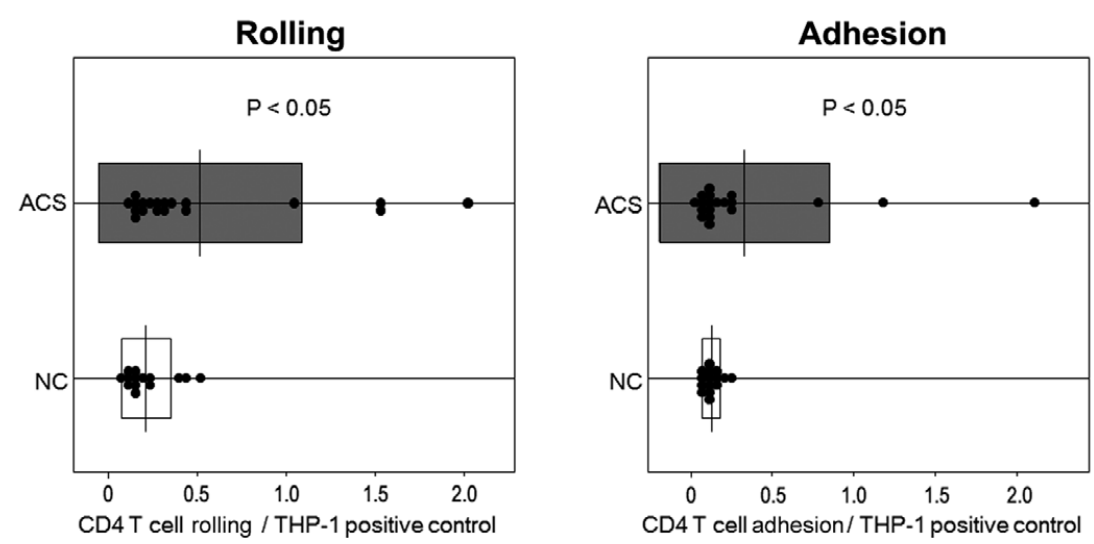

Figure 4. CD4 T cells from acute coronary syndrome (ACS) patients strongly adhere to endothelial cells (ECs). CD4 T cells from ACS and normal controls were drawn onto human umbilical vein ECs pretreated with TNF- $a$ under laminar flow for 10 min. Results are shown as ratios of CD4 T cells to THP-1 cells (control) rolling and adhesion. TNF, tumor necrosis factor.

ecules on CD4 $\mathrm{T}$ cells in ACS culprit coronary arteries have characteristic features, PBMCs were isolated from the culprit arteries using a thrombus-aspirating device and CD4 T-cell adhesion molecule expression was compared with that of peripheral blood CD4 T cells from the same patient. PSGL-1 was more strongly expressed on CD4 T cells in culprit coronary arterial blood than on those in the peripheral blood $(\mathrm{P}<0.001)$. In contrast, integrin $\beta 2$ expression on CD4 T cells was comparable in both coronary and peripheral blood (Figure 1B).

To assess the clinical relevance of PSGL-1-expressing CD4 $\mathrm{T}$ cells in the culprit coronary artery, samples obtained from the thrombus-aspirating device were ana- lyzed by immunohistochemistry. Cell morphology was evaluated by hematoxylin and eosin staining and by labeling with an antibody against the platelet marker CD41. Thrombi were covered with CD41-positive platelets, and necrotic material mixed with cholesterol crystals and variable amounts of inflammatory infiltrate were observed in the aspirates, which were histologically defined as atheromatous plaque by a pathologist (Figure 2A). CD41-positive platelets were rarely detected in the plaques. Many inflammatory cells, such as CD68-positive macrophages and monocytes, MPO-positive neutrophils, and especially CD4-positive T cells, were present in atheromatous plaques. An abundance of PSGL-1-expressing CD4 T cells was 
A

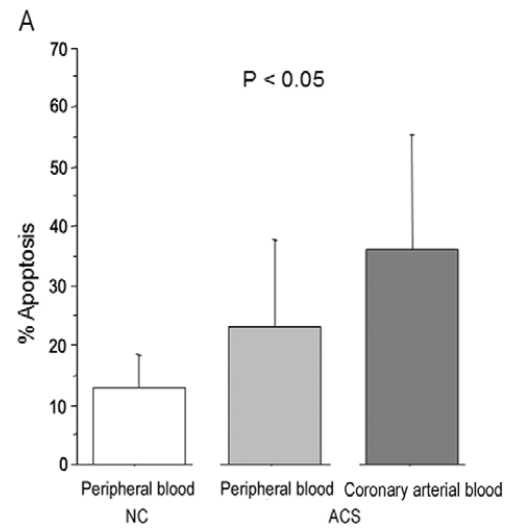

NC

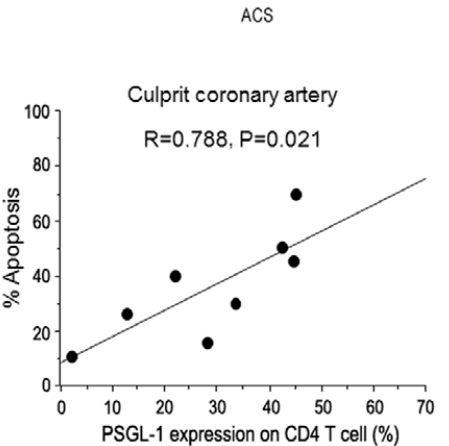

B

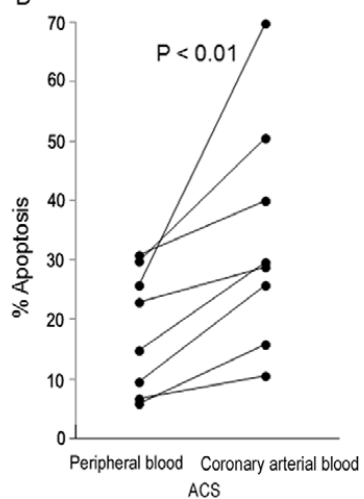

D

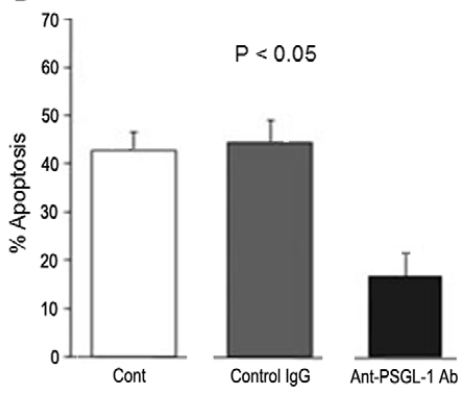

Figure 5. PSGL-1-expressing CD4 T cells in culprit coronary arteries are cytotoxic to endothelial cells (ECs). Fresh CD4 T cells from acute coronary syndrome (ACS) patients and normal controls were incubated on a human umbilical vein EC (HUVEC) monolayer at an effector:target ratio of 5:1. (A) Fraction of apoptotic HUVECs determined after $3 \mathrm{~h}$; results are shown as box plots. (B) Comparison of fractions of apoptotic HUVECs induced by peripheral or culprit coronary arterial blood CD4 T cells from the same ACS patient. (C) Correlation between PSGL-1 expression on CD4 T cells and HUVEC apoptosis in peripheral or culprit coronary arterial blood. (D) CD4 T cells from peripheral blood pretreated with anti-PSGL-1 antibody or control IgG and cocultured with HUVECs for the apoptosis assay.

detected in the culprit coronary arterial plaques (Figure 2B). Through double staining for PSGL-1 and CD4, it was confirmed that many PSGL-1-expressing CD4 T cells existed in the culprit coronary plaque (Figure 2C).

\section{PSGL-1-Expressing CD4 T Cells Bind E- and P-Selectin and Adhere to ECs}

During atherosclerosis development, the binding of T-cell surface PSGL-1 to selectins on activated vascular ECs controls the rate of leukocyte-EC adhesion. A selectinbinding assay was used to determine whether PSGL-1 on CD4 T cells binds to E- or P-selectin. First, T cells from ACS patients were activated by pretreating PBMCs with anti-CD3 antibody and confirming upregulation of CD69, a marker of $\mathrm{T}$ cell activation. PSGL-1 expression on CD4 $\mathrm{T}$ cells was increased via triggering of the T-cell receptor (TCR) (Figure 3A), and activated PSGL-1-expressing CD4 $\mathrm{T}$ cells from ACS patients bound both E- and P-selectin (Figure 3B).

The adhesion characteristics of CD4 T cells were analyzed using activated HUVECs under physiological flow conditions. The number of rolling and adhering CD4 T cells on activated HUVECs was higher in ACS patients than in $\mathrm{NC}(\mathrm{P}<0.05$; Figure 4), suggesting that activated CD4 T cells in ACS patients adhered to activated ECs via the PSGL-1/E- and P-selectin interaction.

\section{PSGL-1-Expressing CD4 T Cells in Culprit Coronary Arteries Induce EC Apoptosis}

To investigate whether PSGL-1 expression by CD4 T cells was associated with plaque instability, their cytotoxicity to ECs was analyzed with an apoptosis assay. PSGL-1expressing CD4 $\mathrm{T}$ cells from culprit coronary arteries induced HUVEC apoptosis more strongly than those from the peripheral blood of ACS patients or $\mathrm{NC}(\mathrm{P}<0.05$; Figure 5A). CD4 $\mathrm{T}$ cells from culprit coronary arterial blood induced HUVEC apoptosis to a greater degree than those from peripheral blood $(\mathrm{P}<0.01$; Figure 5B). We confirmed HUVEC apoptosis for the expression of PARP, a $113-\mathrm{kDa}$ nuclear chromatin-associated enzyme. Apoptotic ECs cocultured with ACS CD4 T cells expressed a high level of PARP comparable to the TNF- $\alpha$ treated positive control, whereas PARP expression was negligible in ECs cocultured with NC CD4 T cells (Figure S1A). In addition, activated caspase-3 was detected in ECs cocultured with ACS CD4 T cells, but was not observed in ECs cocultured with NC CD4 T cells by flow cytometry (Figure S1B).

Furthermore, PSGL-1 expression correlated with CD4 $\mathrm{T}$ cell-induced HUVEC apoptosis in peripheral as well as in culprit coronary arterial blood $(\mathrm{R}=0.566, \mathrm{P}=0.049$ and $\mathrm{R}=0.788, \mathrm{P}=0.021$, respectively; Figure $\mathbf{5 C}$ ). To assess whether CD4 $\mathrm{T}$ cell-induced HUVEC apoptosis was dependent on PSGL-1, an antibody against PSGL-1 was 
included in the apoptosis assay. The antibody treatment inhibited CD4 T cell-induced apoptosis of HUVECs $(\mathrm{P}<0.05$; Figure 5D), demonstrating that PSGL-1-expressing CD4 T cells in the culprit coronary artery of ACS patients induced EC apoptosis in a PSGL-1-dependent manner.

\section{Discussion}

PSGL-1 is a $240-\mathrm{kDa}$ sialomucin that binds L-, P-, and E-selectins expressed on leukocytes; activated $\mathrm{T}$ cells induce the expression of glycosyltransferases, allowing modified PSGL-1 to bind all 3 selectins. Ly6Chi monocytes, a major subset of monocytes found in atherosclerotic mice, strongly express PSGL-1, and PSGL-1 $1^{-/}$apolipoprotein (Apo) $\mathrm{E}^{-/-}$double knockout mice have markedly reduced Ly6 $\mathrm{C}^{\text {hi }}$ monocyte infiltration in atherosclerotic lesions and develop atherosclerosis. ${ }^{22}$ In addition, PSGL-1 ${ }^{-/-}$Apo $\mathrm{E}^{-/-}$ mice showed reduced leukocyte rolling and firm attachment on ECs as compared with PSGL-1 ${ }^{+/+} \mathrm{Apo}^{-/-}$mice. ${ }^{23}$ Meanwhile, PSGL-1 deficiency rescues the impaired vasorelaxation response to acetylcholine of ECs in diet-induced obese mice. ${ }^{24}$ These studies demonstrate that PSGL-1 has an important role in atherosclerosis development. On the other hand, the PSGL-1 interaction partner L-selectin is expressed on leukocytes and mediates lymphocyte rolling. ${ }^{25-27}$ The loss of $\mathrm{L}$-selectin has resulted in a $50 \%$ reduction in lymphocyte homing in L-selectin ${ }^{-1-} \mathrm{ApoE}^{-/-}$double knockout mice. ${ }^{28}$ Moreover, $\mathrm{P}$ - and E-selectin are expressed in chronically inflamed endothelium, and studies of P-selectin ${ }^{-/} \mathrm{ApoE}^{-/-}$and E-selectin ${ }^{-/-} \mathrm{ApoE}^{-/-}$mutants have revealed that atherosclerotic lesions are decreased in these mice. ${ }^{29-31}$

Signals transduced by PSGL-1 have been shown to enhance integrin $\beta 2$ expression on neutrophils and HL60 cells, 32,33 and LFA-1 mediates the binding of helper $\mathrm{T}$ (Th) 1 cells to ICAM-1. ${ }^{34}$ TCR activation and interleukin 12/signal transducer and activator of transcription 4 (STAT4) signaling are important for PSGL-1 synthesis and Th1 cell migration into inflamed tissue. ${ }^{35,36} \mathrm{We}$ previously reported that perimenopausal women have increased numbers of PSGL-1-expressing CD4 T cells, which strongly adhere to ECs and induce apoptosis. ${ }^{20}$ In this study, we investigated adhesion molecules on peripheral blood CD4 T cells and showed that PSGL-1 and integrin $\beta 2$ expression were upregulated in ACS patients as compared with NC. In addition, TCR activation triggered the binding of activated PSGL-1-expressing CD4 T cells to E- or P-selectin in ACS patients, and in them these cells showed greater rolling and adhesion to activated ECs under flow conditions. PSGL-1 likely promotes this adhesion by enhancing integrin $\beta 2$ expression on the ACS CD 4 T-cell surface, thereby contributing to atherosclerotic development.

Recently, the prospective Atherosclerosis Risk in Communities study showed that the PSGL-1 M621 polymorphism is associated with a decreased risk of both coronary artery disease (CAD) and stroke in AfricanAmericans. ${ }^{37}$ In addition, the expression levels of PSGL-1 on $\mathrm{CD} 14^{+} \mathrm{CD} 16^{+}$monocytes are significantly higher in patients with plaque rupture or intracoronary thrombi, as assessed by frequency-domain optical coherence tomography ${ }^{38}$ Platelet-monocyte complex formation after percutaneous coronary intervention (PCI) is more effectively inhibited by blocking PSGL-1 than $\alpha$ (IIb) $\beta(3)$ (GPIIb/IIIa) or $\alpha \mathrm{M} \beta(2)$ (Mac1). ${ }^{39}$ Our observation in this study of numerous PSGL-1-positive cells in plaques from culprit coronary arteries suggests that platelet-monocyte complex formation depends largely on PSGL-1.

Studies of culprit coronary arteries from cardiac sudden death cases have revealed that the primary pathology of vulnerable plaques arises from plaque rupture $(60 \%)$ and superficial erosion (40\%). ${ }^{9,40,41} \mathrm{EC}$ apoptosis in the fibrous cap covering stable plaques can cause plaque destabilization and increase ACS risk. ${ }^{6,7}$ In addition to an adhesive function, PSGL-1 contributes to the efficient homing of resting (naïve and central memory) $\mathrm{T}$ cells to secondary lymphoid organs via PSGL-1-C-C motif chemokine ligand (CCL) 21 or -CCL19 interactions and proliferation. ${ }^{\mathbf{4 2 , 4 3}}$ Recently, it was reported that the inhibition of P-selectin with anti-P-selectin monoclonal antibody reduced myocardial damage during PCI in patients with non-ST-segment elevation myocardial infarction. ${ }^{44} \mathrm{We}$ reported that interferon $\gamma$ - and TNF $\alpha$-producing activated CD4 T cells are attracted to vulnerable plaques by the dendritic cell chemokines CCL19 and CCL21, ${ }^{11}$ and therefore we examined culprit coronary arterial blood, thrombi, and plaque samples in the present study. We observed an abundance PSGL-1-expressing CD4 T cells in culprit coronary arterial plaques. Furthermore, these CD4 T cells potently induced PSGL-1-dependent EC apoptosis. Given that adherent and transmigrating PSGL-1-expressing CD4 T cells in culprit coronary arteries are activated in situ and may cause atherosclerotic plaque instability and damage to tissues containing EC and VSMCs, blocking PSGL-1 is a potential therapeutic approach for preventing cardiovascular events and death in ACS patients.

\section{Acknowledgments}

We thank Dr. Keiko Fukushima, Dr. Junichi Yamaguchi and Dr. Hiroyuki Arashi from the Catheterization Laboratory, Department of Cardiology, Tokyo Women's Medical University for providing the blood and tissue samples retrieved from thrombus-aspiration therapy of culprit coronary arteries, and Yasuko Hasegawa from the Tokyo Metropolitan Institute of Gerontology for assistance with immunohistochemistry.

\section{Disclosures}

None.

\section{Names of Grants}

Global COE program, Multidisciplinary Education and Research Center for Regenerative Medicine (MERCREM), and the Ministry of Education, Culture, Sports Science, and Technology (MEXST) to K.K.; and an Open Research grant from the Japan Research Promotion Society for Cardiovascular Disease, and grants from the Global COE program, MERCREM, MEXST, and a Grant-in-Aid for Scientific Research (C) to K.S.

\section{References}

1. Sato K. Helper T cell diversity and plasticity. Circ $J$ 2014; 78: $2843-2844$

2. Ait-Oufella H, Sage AP, Mallat Z, Tedgui A. Adaptive (T and B cells) immunity and control by dendritic cells in atherosclerosis. Circ Res 2014; 114: 1640-1660.

3. Swirski FK, Nahrendorf M. Leukocyte behavior in atherosclerosis, myocardial infarction, and heart failure. Science 2013; 339: $161-166$.

4. Lichtman AH, Binder CJ, Tsimikas S, Witztum JL. Adaptive immunity in atherogenesis: New insights and therapeutic approaches. J Clin Invest 2013; 123: 27-36.

5. Galkina E, Ley K. Immune and inflammatory mechanisms of atherosclerosis (*). Annu Rev Immunol 2009; 27: 165-197.

6. Durand E, Scoazec A, Lafont A, Boddaert J, Al Hajzen A, Addad F, et al. In vivo induction of endothelial apoptosis leads to vessel thrombosis and endothelial denudation: A clue to the 
understanding of the mechanisms of thrombotic plaque erosion. Circulation 2004; 109: 2503-2506.

7. Choy JC, Granville DJ, Hunt DW, McManus BM. Endothelial cell apoptosis: Biochemical characteristics and potential implications for atherosclerosis. J Mol Cell Cardiol 2001; 33: 1673-1690.

8. Virmani R, Kolodgie FD, Burke AP, Farb A, Schwartz SM. Lessons from sudden coronary death: A comprehensive morphological classification scheme for atherosclerotic lesions. Arterioscler Thromb Vasc Biol 2000; 20: 1262-1275.

9. van der Wal AC, Becker AE, van der Loos CM, Das PK. Site of intimal rupture or erosion of thrombosed coronary atherosclerotic plaques is characterized by an inflammatory process irrespective of the dominant plaque morphology. Circulation 1994; 89: $36-44$.

10. Sato K, Nuki T, Gomita K, Weyand CM, Hagiwara N. Statins reduce endothelial cell apoptosis via inhibition of TRAIL expression on activated CD4 T cells in acute coronary syndrome. Atherosclerosis 2010; 213: 33-39.

11. Erbel C, Sato K, Meyer FB, Kopecky SL, Frye RL, Goronzy JJ, et al. Functional profile of activated dendritic cells in unstable atherosclerotic plaque. Basic Res Cardiol 2007; 102: 123-132.

12. Sato K, Niessner A, Kopecky SL, Frye RL, Goronzy JJ, Weyand CM. TRAIL-expressing T cells induce apoptosis of vascular smooth muscle cells in the atherosclerotic plaque. J Exp Med 2006; 203: 239-250.

13. Pryshchep S, Sato K, Goronzy JJ, Weyand CM. T cell recognition and killing of vascular smooth muscle cells in acute coronary syndrome. Circ Res 2006; 98: 1168-1176.

14. Niessner A, Sato K, Chaikof EL, Colmegna I, Goronzy JJ, Weyand CM. Pathogen-sensing plasmacytoid dendritic cells stimulate cytotoxic T-cell function in the atherosclerotic plaque through interferon-alpha. Circulation 2006; 114: 2482-2489.

15. Nakajima T, Schulte S, Warrington KJ, Kopecky SL, Frye RL, Goronzy JJ, et al. T-cell-mediated lysis of endothelial cells in acute coronary syndromes. Circulation 2002; 105: 570-575.

16. Zhou X, Stemme S, Hansson GK. Evidence for a local immune response in atherosclerosis. CD4+ T cells infiltrate lesions of apolipoprotein-E-deficient mice. Am J Pathol 1996; 149: 359366.

17. Rao RM, Yang L, Garcia-Cardena G, Luscinskas FW. Endothelial-dependent mechanisms of leukocyte recruitment to the vascular wall. Circ Res 2007; 101: 234-247.

18. Libby P. Inflammation in atherosclerosis. Nature 2002; 420: $868-874$.

19. Johnson-Tidey RR, McGregor JL, Taylor PR, Poston RN. Increase in the adhesion molecule P-selectin in endothelium overlying atherosclerotic plaques: Coexpression with intercellular adhesion molecule-1. Am J Pathol 1994; 144: 952-961.

20. Gomita K, Sato K, Yoshida M, Hagiwara N. PSGL-1-expressing CD4 T cells induce endothelial cell apoptosis in perimenopausal women. J Atheroscler Thromb 2012; 19: 227-236.

21. Mori D, Ishii H, Kojima C, Nitta N, Nakajima K, Yoshida M. Cilostazol inhibits monocytic cell adhesion to vascular endothelium via upregulation of cAMP. J Atheroscler Thromb 2007; 14: $213-218$.

22. An G, Wang H, Tang R, Yago T, McDaniel JM, McGee S, et al. $\mathrm{P}$-selectin glycoprotein ligand-1 is highly expressed on Ly-6Chi monocytes and a major determinant for Ly-6Chi monocyte recruitment to sites of atherosclerosis in mice. Circulation 2008; 117: $3227-3237$

23. Luo W, Wang H, Ohman MK, Guo C, Shi K, Wang J, et al. $\mathrm{P}$-selectin glycoprotein ligand-1 deficiency leads to cytokine resistance and protection against atherosclerosis in apolipoprotein $\mathrm{E}$ deficient mice. Atherosclerosis 2012; 220: 110-117.

24. Wang H, Luo W, Wang J, Guo C, Wang X, Wolffe SL, et al. Obesity-induced endothelial dysfunction is prevented by deficiency of P-selectin glycoprotein ligand-1. Diabetes 2012; 61: 32193227.

25. McEver RP, Cummings RD. Role of PSGL-1 binding to selectins in leukocyte recruitment. J Clin Invest 1997; 100: S97-S103.

26. Asa D, Raycroft L, Ma L, Aeed PA, Kaytes PS, Elhammer AP, et al. The P-selectin glycoprotein ligand functions as a common human leukocyte ligand for P- and E-selectins. J Biol Chem 1995; 270: $11662-11670$.

27. Sako D, Chang XJ, Barone KM, Vachino G, White HM, Shaw $\mathrm{G}$, et al. Expression cloning of a functional glycoprotein ligand for P-selectin. Cell 1993; 75: 1179-1186.
28. Galkina E, Kadl A, Sanders J, Varughese D, Sarembock IJ, Ley $\mathrm{K}$. Lymphocyte recruitment into the aortic wall before and during development of atherosclerosis is partially L-selectin dependent. J Exp Med 2006; 203: 1273-1282.

29. Galkina E, Ley K. Vascular adhesion molecules in atherosclerosis. Arterioscler Thromb Vasc Biol 2007; 27: 2292-2301.

30. Ley K, Kansas GS. Selectins in T-cell recruitment to non-lymphoid tissues and sites of inflammation. Nat Rev Immunol 2004; 4: $325-335$.

31. Dong ZM, Chapman SM, Brown AA, Frenette PS, Hynes RO, Wagner DD. The combined role of P- and E-selectins in atherosclerosis. J Clin Invest 1998; 102: 145-152.

32. Xu T, Liu W, Luo J, Li C, Ba X, Ampah KK, et al. Lipid Raft is required for PSGL-1 ligation induced HL-60 cell adhesion on ICAM-1. PLoS One 2013; 8: e81807.

33. Wang XG, Cheng YP, Ba XQ. Engagement of PSGL-1 enhances beta(2)-integrin-involved adhesion of neutrophils to recombinant ICAM-1. Acta Pharmacol Sin 2006; 27: 617-622.

34. Atarashi K, Hirata T, Matsumoto M, Kanemitsu N, Miyasaka M. Rolling of Th1 cells via p-selectin glycoprotein ligand-1 stimulates LFA-1-Mediated cell binding to ICAM-1. J Immunol 2005; 174: 1424-1432.

35. Lim YC, Xie H, Come CE, Alexander SI, Grusby MJ, Lichtman AH, et al. IL-12, STAT4-dependent up-regulation of CD4(+) T cell core 2 beta-1,6-n-acetylglucosaminyltransferase, an enzyme essential for biosynthesis of P-selectin ligands. J Immunol 2001; 167: $4476-4484$.

36. Hirata T, Merrill-Skoloff G, Aab M, Yang J, Furie BC, Furie B. P-Selectin glycoprotein ligand 1 (PSGL-1) is a physiological ligand for E-selectin in mediating $\mathrm{T}$ helper 1 lymphocyte migration. J Exp Med 2000; 192: 1669-1676.

37. Volcik KA, Ballantyne CM, Coresh J, Folsom AR, Boerwinkle E. Specific P-selectin and P-selectin glycoprotein ligand-1 genotypes/haplotypes are associated with risk of incident CHD and ischemic stroke: The Atherosclerosis Risk in Communities (ARIC) study. Atherosclerosis 2007; 195: e76-e82.

38. Ozaki Y, Imanishi T, Teraguchi I, Nishiguchi T, Orii M, Shiono $\mathrm{Y}$, et al. Association between P-selectin glycoprotein ligand-1 and pathogenesis in acute coronary syndrome assessed by optical coherence tomography. Atherosclerosis 2014; 233: 697-703.

39. Fernandes LS, Conde ID, Wayne Smith C, Kansas GS, Snapp KR, Bennet N, et al. Platelet-monocyte complex formation: Effect of blocking PSGL-1 alone, and in combination with $\alpha \operatorname{IIb} \beta 3$ and $\alpha \mathrm{M} \beta 2$, in coronary stenting. Thromb Res 2003; 111: $171-177$.

40. Usui E, Yonetsu T, Murai T, Kanaji Y, Matsuda J, Hoshino M, et al. Prevalence of thin-cap fibroatheroma in relation to the severity of anatomical and physiological stenosis. Circ J 2017; 81: $1816-1823$.

41. Konishi T, Funayama N, Yamamoto T, Morita T, Hotta D, Nomura R, et al. Pathological quantification of carotid artery plaque instability in patients undergoing carotid endarterectomy. Circ J 2018; 82: 258-266.

42. Veerman KM, Carlow DA, Shanina I, Priatel JJ, Horwitz MS, Ziltener HJ. PSGL-1 regulates the migration and proliferation of CD8(+) T cells under homeostatic conditions. J Immunol 2012; 188: $1638-1646$.

43. Veerman KM, Williams MJ, Uchimura K, Singer MS, Merzaban JS, Naus S, et al. Interaction of the selectin ligand PSGL-1 with chemokines CCL21 and CCL19 facilitates efficient homing of T cells to secondary lymphoid organs. Nat Immunol 2007; 8: $532-$ 539.

44. Tardif JC, Tanguay JF, Wright SS, Duchatelle V, Petroni T, Gregoire JC, et al. Effects of the P-selectin antagonist inclacumab on myocardial damage after percutaneous coronary intervention for non-ST-segment elevation myocardial infarction: Results of the SELECT-ACS trial. J Am Coll Cardiol 2013; 61: 2048-2055.

\section{Supplementary Files}

\section{Supplementary File 1}

Figure S1. PSGL-1-expressing CD4 T cells induce EC apoptosis in ACS via caspase-3 activation.

Please find supplementary file(s);

http://dx.doi.org/10.1253/circj.CJ-17-1270 